\title{
Colaboração em Sala de Aula: Uma proposta baseada na Criação e Resolução de Questionários Online
}

\author{
Neide Aparecida Alves de Medeiros ${ }^{1}$, Elvis Medeiros de Melo ${ }^{1}$, Edith Cristina da \\ Nóbrega ${ }^{1}$, Nathalie Rose Ramos da Fonseca Araújo ${ }^{1}$, Rodolfo Morais da Costa ${ }^{1}$, \\ Isabel Dillmann Nunes ${ }^{1}$, Maria Cristina Leandro de Paiva ${ }^{2}$ \\ Instituto Metrópole Digital - Universidade Federal do Rio Grande do Norte (UFRN) \\ Av. Sen. Salgado Filho, 3000 - Lagoa Nova, CEP: 59.078-970 - Natal - RN - Brasil \\ 2Departamento de Fundamentos e Políticas da Educação - UFRN - Natal - RN - Brasil \\ \{neidemedeiros, elvismedeiros.mm, nathalieroses, crislean6\}@gmail.com, \\ (edithecn, rodolfocosta) dufrn.edu.br, beleimd.ufrn.br
}

\begin{abstract}
The practice of solving pre-test exercises is common in the school environment. For contemporary students, if the process of answering questionnaires is not from meaningful practices, it can become tiring, as well as not conducive to the construction of knowledge. The present work proposed the re-signification of the elaboration of the questionnaires based on collaboration with computational support. In this way, students have elaborated questions using Google Forms. The reports of the experiences reveal a collaborative and dynamic work, in which the student was protagonist of his learning.
\end{abstract}

Resumo. A prática de resolução de exercícios que antecedem as provas é comum no ambiente escolar. Para alunos contemporâneos, se o processo de responder questionários não for a partir de práticas significativas, esta poderá se tornar cansativa, além de não propiciar a construção de conhecimento. $O$ presente trabalho propôs a ressignificação da elaboração dos questionários baseados na colaboração com suporte computacional. Desta forma, os alunos elaboraram questões utilizando o Google Formulários. Os relatos das experiências revelam um trabalho colaborativo e dinâmico, no qual o aluno foi protagonista da sua aprendizagem.

\section{Introdução}

No atual sistema educacional, geralmente alunos de diversas escolas reclamam da grande quantidade de exercícios que são propostos à resolução em época de provas, o que torna a atividade de responder questões e estudar para as avaliações, enfadonha e cansativa. O processo de responder questionários se resume a uma atividade mecânica, na qual, o aluno cumpre uma tarefa independente das possibilidades de aprendizagem.

Mesmo que os professores tentem fazer essa atividade utilizando um recurso digital, transferindo a atividade do papel para uma plataforma online, não promove modificações significativas no processo de ensino e aprendizagem, muito menos na prática. Trata-se do mesmo processo, só que no ambiente digital. Essa modernidade já é apontada por Morin (2012) quando fala sobre o uso das tecnologias só por estar em alta, ou a ilusão de que a tecnologia vem para resolver todos os problemas educacionais. 
VII Congresso Brasileiro de Informática na Educação (CBIE 2018)

Anais do XXIV Workshop de Informática na Escola (WIE 2018)

Essa concepção não se sustenta, visto que o ato de apenas responder uma determinada quantidade de exercícios dificilmente proporcionará uma aprendizagem ativa e significativa, colocando o aluno como centro do processo.

Partindo para concepções de colaboração, o termo aprendizagem na aprendizagem colaborativa se refere a metodologias interativas entre o aluno em conjunto com o professor para que estabeleçam buscas, compreensão e interpretação da informação de assuntos determinados [Dunne e Honts 1998]. Será que uma atividade de elaboração de questões colaborativa ajudaria os alunos em um engajamento melhor nesse processo? E com suporte de tecnologia?

Diante desse cenário, a problemática identificada foi "Como tornar o processo de responder questionários online mais engajador, colaborativo e mais significativo para os alunos?". Foi proposto a solução intitulada War Quiz, aplicada com alunos de $8^{\circ}$ e $9^{\circ}$ anos em duas escolas privadas de Natal, Rio Grande do Norte. Desta forma, os estudantes, divididos em grupos, elaboraram as suas próprias questões com suporte da ferramenta digital Google Formulários ${ }^{l}$ de maneira colaborativa, além de um encurtador de links, para o compartilhamento dos documentos com os estudantes. De acordo com Gudwin (2018) esse tipo de proposta torna o aluno engajado com atitude mais intensa e participativa. Esse tipo de estratégia didática pode contribuir com o desenvolvimento de criatividade como conteúdo na educação, no contexto do Século XXI, sendo umas das competências necessárias para o cidadão do futuro [UNESCO 2015].

Dessa forma, o presente artigo está estruturado da seguinte forma: além desta seção introdutória, na seção 2 abordamos a importância de práticas colaborativas na educação, na seção 3 tratamos de software colaborativo, na seção 4 a metodologia utilizada nesta prática de trabalho, a seção 5 detalha os resultados e discussões sobre as práticas nas duas realidades, e por fim a seção 6 apresenta as considerações sobre a proposta e os possíveis trabalhos futuros.

\section{Aprendizagem Colaborativa}

Segundo Dillenbourg (1999), a aprendizagem colaborativa trata-se de uma situação de aprendizagem na qual duas ou mais pessoas aprendem ou tentam aprender algo juntas. Compreendido isso, sabe-se que a aprendizagem colaborativa não se trata de práticas contemporâneas, derivam de diversas referências do pensar e do fazer pedagógico.

Com isso, é válido compreender, no limiar dos avanços das abordagens pedagógicas, no que concerne a aprendizagem colaborativa, as reflexões de Piaget (1990), ao trazer, na teoria construtivista de aprendizagem baseada na Epistemologia Genética, a ação, ou mais especificamente a interação, como requisito fundamental para sua prática. Desse modo, nota-se uma mudança de perspectiva, em que o aluno passa a ser protagonista de sua aprendizagem, desconstruindo a condição passiva imposta outrora; e o professor passa a ser agente estimulante para o desequilíbrio cognitivo, visando um reequilíbrio mais elevado, mais evoluído do aluno, descaracterizando o perfil de detentor do conhecimento do professor.

\footnotetext{
${ }^{1}$ Disponível em: <gsuite.google.com/Google/Formulários>. Acesso em: 06 jun. 2018
} 
VII Congresso Brasileiro de Informática na Educação (CBIE 2018)

Anais do XXIV Workshop de Informática na Escola (WIE 2018)

Complementando as ideias de Piaget, Vygotsky (1998) compreende a aprendizagem como construída pelas interações do indivíduo com outrem. Estas interações sociais, fator inato do convívio social, seriam as principais desencadeadoras do aprendizado. Sendo assim, o processo de mediação faz com que dois ou mais sujeitos colaborem em uma atividade, exercitando o quesito interpessoal do momento de construção do conhecimento, por sua vez, favorecendo a reelaboração de cada indivíduo, fortalecendo o quesito intrapessoal. Entende-se que propostas de aprendizagem colaborativa com suporte de tecnologia, como o War Quiz, estimulam novos conflitos cognitivos, uma vez que no momento da interferência de outros indivíduos na efetivação da proposta atuam para o sujeito (individual) como agente do crescimento e evolução do que se aprende.

Ainda sobre a aprendizagem colaborativa, de acordo com Novak e Cañas (2010), "há um corpus de pesquisa em expansão mostrando que, quando os estudantes trabalham em pequenos grupos e se esforçam em conjunto para aprenderem um tema, eles alcançam resultados cognitivos e afetivos positivos". Sendo assim, deve-se considerar que na aprendizagem colaborativa o esforço mútuo e a geração de conflitos cognitivos, fomentam soluções e evoluções quanto ao aprender. Porém, para isso seja efetivado, há uma necessidade de diversidade nos grupos.

\section{Software Colaborativo}

Após compreender as diversas visões acerca da aprendizagem colaborativa que corroboram com nossa proposta, é válido entender alguns conceitos consoantes a nosso trabalho. Por tratamos aqui de uma proposta colaborativa que utiliza o computador como ferramenta, faz-se indispensável o entendimento acerca do termo software colaborativo ou groupware. Segundo Ellis et al. (1991), trata-se de um sistema baseado em computador que auxilia grupos de pessoas envolvidas em tarefas comuns (ou objetivos) e que provê interface para um ambiente compartilhado.

Pode-se definir, ainda, como um conjunto de aplicações, síncronas e assíncronas, respectivamente, integradas em um ambiente. Para Honório e Scortegagna (2017) são nesses espaços que os indivíduos podem interagir e trabalhar de forma colaborativa. Porém, é importante salientar que para a efetivação do uso do groupware, este deve ser claro e acessível, além disso, os sujeitos/usuários envolvidos devem reconhecer a ausência de hierarquia formal, o respeito mútuo, o objetivo comum do uso e a liberdade para exposição de ideias, questionamentos no ambiente e no modelo de aprendizagem que norteia essas aplicações.

Mesmo diante das facilidades trazidas pelos softwares colaborativos, reconhecese que a maioria das práticas pedagógicas atuais e, principalmente, as que envolvem novas tecnologias, preferem ou enfatizam a aprendizagem individual. Por isso, surgiu a necessidade de pensar uma proposta que realmente fosse coletiva e colaborativa, mas que não se limitasse somente a isso, mas fizesse com que o aluno estivesse na condição de protagonista de sua aprendizagem. Sobre tal aspecto, temos as reflexões de Scharle e Szabó (2000, p. 4), ao apontar que "a autonomia do aprendiz envolve o direito de tomar decisões, o que requer habilidade e liberdade para monitorar seus próprios conteúdos".

Neste sentido, o estudante, além de ser responsável por sua aprendizagem, tornase coautor da aprendizagem de seus pares Lima et al. (2016). Considerando a aquisição 
VII Congresso Brasileiro de Informática na Educação (CBIE 2018)

Anais do XXIV Workshop de Informática na Escola (WIE 2018)

da autonomia do aluno, o pensamento da aprendizagem colaborativa possibilita formar alunos para além dos muros da escola, pois ele terá uma formação holística e saberá trabalhar em pares, avaliando os problemas de forma cooperativa. Na dinâmica da sala de aula, trabalhar com a colaboração com suporte de tecnologia, propiciará para o aluno troca de conhecimentos, interação com os pares e diálogo reflexivo, permeados por momentos lúdicos que tornarão o processo de ensino e aprendizagem mais significativo, enquanto o professor mediará todas as possibilidades de aprendizagem que a colaboração proporciona.

\section{Metodologia}

Segundo Ferreira e Santos (2008), no processo de elaboração de problemas, os alunos: reconhecem padrões, porque usualmente caos e complexidade são causados por padrões simples, que quando reconhecidos levam à solução do problema; ver de outros modos, que significa procurar por padrões a partir de diferentes perspectivas: lógica, organizacional, procedimental, experimental, holística, especulativa, etc.; fazer conexões, ideias criativas são o resultado da sinergia que ocorre entre pensamentos; tirar vantagem de uma chance, o que significa calcular riscos, deste modo tira-se proveito de uma oportunidade que pode permitir caminhar na direção de uma solução criativa. Além desse tipo de atividade, propusemos para que, através de ferramentas colaborativas, os alunos realizassem essa atividade em ambiente online.

Sendo assim, o percurso desta proposta colaborativa é: i) elaboração do mapa mental para visualizar tudo que seria utilizado nesta atividade; ii) planejamento do tempo de cada atividade; iii) pré-configuração dos formulários online (Google Forms); iv) compartilhamento do formulário com os integrantes de cada grupo.

Na figura 1 é apresentado o mapa mental elaborado pela equipe no momento de planejamento da atividade.

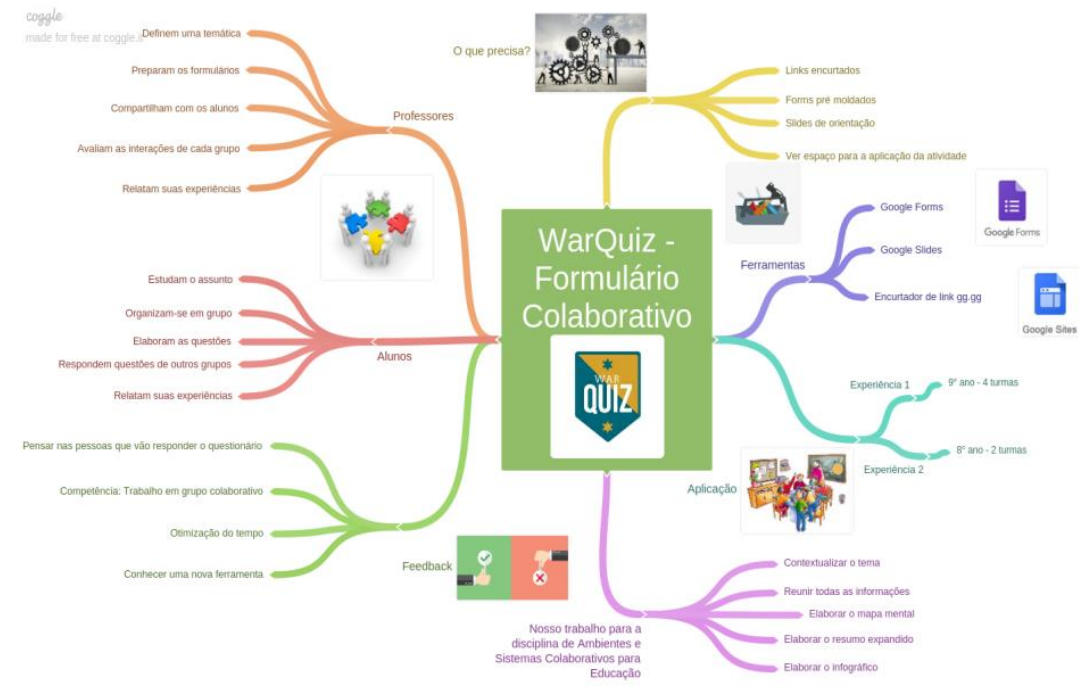

Figura 1. Mapa Mental ${ }^{2}$ elaborado pelos autores

\footnotetext{
${ }^{2}$ Disponível em: < https://goo.gl/HH5z44> Acesso em: 06 jun. 2018
} 
O planejamento e elaboração desta atividade foi realizado de maneira colaborativa. Inicialmente a prática foi planejada para uma ou duas aulas, aproximadamente 100 minutos, mas em alguns contextos ela teve de se prolongar. Cada professor preparou os formulários Google para que ficassem pré-formatados a fim de ganhar tempo para desenvolver a prática em suas salas. Os alunos deveriam acessar seus formulários para criar suas próprias questões através de um link encurtado disponibilizado pelo professor. Os professores se reuniram para planejar a realização de tal atividade.

Com a proposta do War Quiz os professores: i) definem uma temática, ou seja, esse tipo de atividade pode ser realizada em qualquer disciplina; ii) preparam os formulários para que fiquem pré-formatados da forma como o professor deseja que sejam elaboradas as perguntas, quais sejam: discursivas, objetivas, de seleção múltipla, etc.; iii) preparam os links encurtados, a fim de otimizar tempo na digitação da URL pelos alunos; iv) avaliam as interações de cada grupo, mediando na medida do possível e gerenciando possíveis conflitos; v) relatam suas experiências através de um questionário online. Já os alunos precisam: i) escolher o assunto, de preferência algum assunto já estudado em sala de aula proposto pelo professor, pois a atividade tem caráter de retomada; ii) organizam-se em grupos, para que a competência proposta pelo groupware seja colocada em ação; iii) elaboram as questões de acordo com as orientações do professor mediador; iv) respondem as questões dos outros grupos, a fim de gerar feedback sobre o conteúdo e o modelo das questões; v) relatam suas experiências através de questionário online.

A atividade foi aplicada em duas realidades distintas. Na primeira, em quatro turmas do $9^{\circ}$ ano, a sugestão foi a elaboração de questões com diferentes níveis de dificuldade para o conteúdo de Matemática de equações do $2^{\circ}$ grau. Na segunda, em quatro turmas de $8^{\circ}$ ano e seis turmas de $9^{\circ}$ ano foram trabalhados assuntos relacionados aos temas de iniciação científica de seus trabalhos do trimestre, tendo como sugestão a utilização da estatística para a composição das questões e levantamento de dados.

\section{Resultados e Discussões}

Nessa seção, serão apresentadas as duas aplicações e os resultados obtidos por meio da proposta do War Quiz. Os professores, dessas duas realidades, escolheram os grupos para que todos estivessem nivelados quanto ao saber necessário para a elaboração das questões, durante a execução desta proposta.

\subsection{Primeira Aplicação}

Os modelos de questionários pré-formatados no Google Formulários foram compartilhados com os alunos no início da aula. Cada grupo teve que elaborar de 3 a 4 questões, quantidades diferentes foram definidas de acordo com número de alunos de cada sala, pois isto interferiria na quantidade de questões que os alunos deveriam resolver para completar a atividade.

Os alunos preferiram elaborar e resolver as questões de seu grupo no caderno e, só depois que todos entenderam como se dava sua resolução, é que eles alimentaram o formulário compartilhado com os professores. Os alunos fizeram uso de notebooks, tablets e até celulares para inserir as questões no Google Formulários. Alguns alunos 
VII Congresso Brasileiro de Informática na Educação (CBIE 2018)

Anais do XXIV Workshop de Informática na Escola (WIE 2018)

ficaram curiosos e perguntaram como eles também poderiam criar seus próprios formulários online. Essa curiosidade demonstra o interesse dos alunos por essa atividade colaborativa.

$\mathrm{Na}$ aula seguinte, todos os formulários foram disponibilizados para que os alunos pudessem responder às questões dos demais grupos. O professor teve papel de mediador durante toda a atividade, tirando dúvidas e observando como se dava a interação entre os alunos, tanto na elaboração como na resolução das questões. Durante a atividade todos os alunos resolveram contribuir e participaram ativamente na resolução das questões, conforme Figura 2. Normalmente, percebe-se que um ou outro aluno não tem interesse ou não colabora, mas isso não aconteceu durante esta experiência, pois os alunos estavam envolvidos na construção das questões. Os estudantes consideraram essa proposta como um desafio e cumpriram todas as etapas. Um desafio colaborativo que contribuiu para a assimilação do conteúdo e a interação dos alunos.

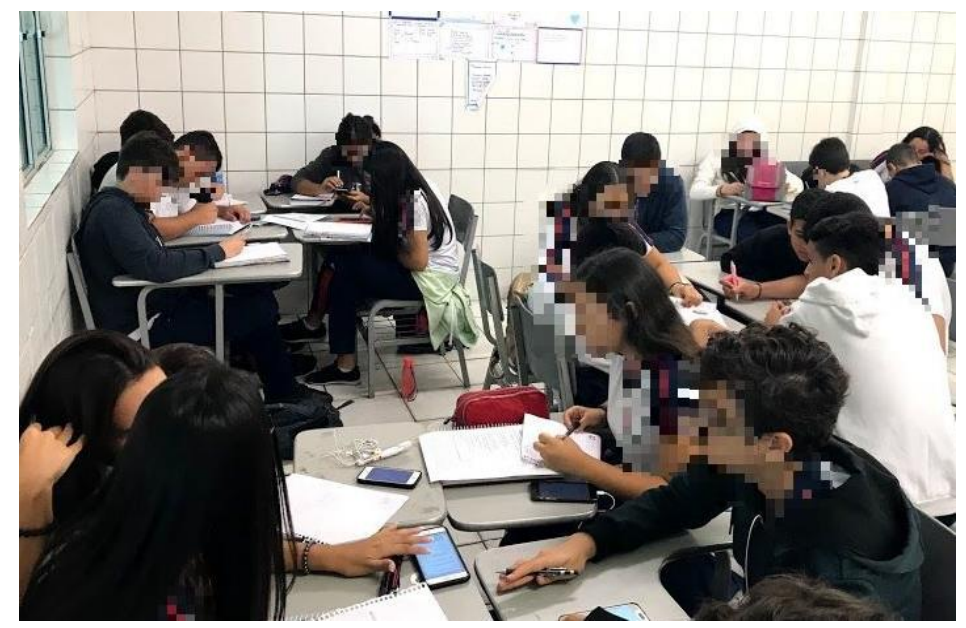

Figura 2. Alunos resolvendo as questões colaborativamente

Nesse processo, o professor foi de fato um mediador do conhecimento. Antes da experiência, ele ministrou a aula sobre Equação do $2^{\circ}$ grau para fundamentar os alunos. Quando ele recebeu a proposta para realizar a atividade colaborativa, entendeu como uma oportunidade de sistematizar o conhecimento dos alunos. Contudo, essa sistematização aconteceu de uma maneira interativa e lúdica, fato que tornou a aprendizagem significativa. O professor relatou que: "sem dúvida, a atividade foi um sucesso. A forma colaborativa de se trabalhar as Equações do $2^{\circ}$ grau foi o ponto alto do projeto. Os alunos puderam aprender e ensinar entre eles, além de despertar o lado criativo na elaboração das questões. Foi possível perceber o total interesse entre eles, as estratégias feitas, a motivação e o empenho foram pontos de destaque no decorrer da atividade". O relato do professor demonstra o quanto a atividade colaborativa contribuiu com a sistematização do conteúdo ministrado em sala de aula. O professor concluiu: "Entendo que trabalhos como este são feitos para agregar cada vez mais no desenvolvimento de cada aluno."

Um ponto importante, destacado pelo professor posteriormente a esta atividade, após as avaliações com o assunto de equações do $2^{\circ}$ grau foi que o exercício desta criação de questões colaborativas promoveu um aprendizado significativo tanto para os 
VII Congresso Brasileiro de Informática na Educação (CBIE 2018)

Anais do XXIV Workshop de Informática na Escola (WIE 2018)

alunos, como para ele próprio. Erros primários que os alunos vinham cometendo anteriormente foram minimizados com esta atividade. E para o professor, inverter o processo de criação e revisão da elaboração das questões foi algo que ele ainda não havia imaginado que pudesse dar certo.

Os alunos se mostraram engajados durante todo o processo. Eles foram os protagonistas de toda a atividade e trabalharam de forma colaborativa para construir um questionário que seria respondido por outros grupos. Percebeu-se ainda que algumas questões apresentaram erros em sua formulação, porém essa situação foi contornada pelo professor, que solicitou aos alunos que reelaborassem essas equações, a fim de encontrar um resultado válido. Ao final da atividade, foi oportunizado aos alunos um novo questionário para que eles pudessem expressar como havia sido a atividade para eles e o que deveria ser mudado. Os relatos dos alunos são contagiantes, como veremos a seguir:

- "A experiência foi ótima e espero que tenhamos ela de novo em outras matérias como física e geometria."

- "Para mim, foi ótimo participar desta atividade, a qual me proporcionou uma melhor aprendizagem do conteúdo e transformou algo metódico, como a aplicação da matéria em algo dinâmico."

- "Participar de trabalhos divertidos e dinamizados numa aula que requer prática consegue instigar o aluno a participar de aulas que não faça com que o contexto abordado em sala se torne chato."

A fala dos alunos justifica a importância de trabalhos colaborativos na prática pedagógica, que se adequa a qualquer disciplina e promove uma aprendizagem baseada na interação.

\subsection{Segunda Aplicação}

Houve colaboração no momento de realização da atividade, tanto virtual, quanto presencialmente, por meio das trocas e combinados iniciais.

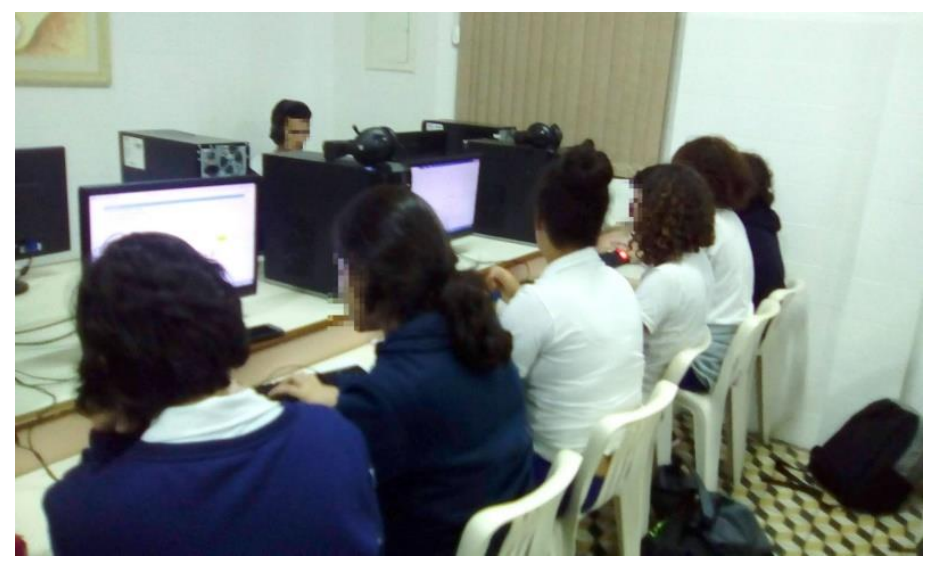

Figura 3. Alunos interagindo dentro e fora do Espaço Virtual.

Neste contexto, os alunos foram indicados a produzirem suas questões em relação aos conteúdos de sua pesquisa científica do trimestre. As aulas com o professor 
VII Congresso Brasileiro de Informática na Educação (CBIE 2018)

Anais do XXIV Workshop de Informática na Escola (WIE 2018)

aplicador acontecem a cada quinzena, na qual os estudantes aprendem lições sobre o Tratamento da Informação ${ }^{3}$ e o uso de artifícios estatísticos para comporem suas atividades. No caso, a sessão teve o tema da proposta, na qual eles precisam elaborar questões de cunho objetivo para a coleta de dados.

Algumas recomendações foram feitas antes do momento da elaboração das cinco questões, como por exemplo, que trouxessem artifícios de suas pesquisas científicas, além de trazer artifícios da estatística.

Foram distribuídos, no início da prática, papéis com os links dos formulários compartilhados e os objetivos da elaboração das questões para cada grupo. No momento inicial, houve um pouco de resistência no uso da ferramenta, como questões de vários usuários editando o mesmo campo de texto. Diante disso, muitos estudantes se envolveram e tiveram de organizar o grupo para o trabalho dentro do tempo estipulado. Além disso, diversos grupos optaram por designar uma pessoa para digitar o conteúdo no formulário colaborativo, além de dividir as atividades para cada componente. Aqui, conceitos relacionados a groupware foram observados, como a colaboração mediada por ambiente online colaborativo.

Ao final das aulas, aplicamos um instrumento de avaliação da prática. Entre os que responderam esse questionário, $88,9 \%$ afirmaram querer que tenham mais atividades como essa, $90 \%$ dos alunos enxergaram possibilidades acadêmicas de coleta de dados com a ferramenta, 89\% julgou importante que houvessem atividades colaborativas com suporte de tecnologia. Dentre as falas registradas, a mais presente foi a comunicação preliminar e distribuição de tarefas para a conclusão dos trabalhos em grupo.

Apesar de resistência inicial, de alguns estudantes para uso da ferramenta, 70\% alegaram já conhecer o Google formulários. 90\% julga importante que atividades colaborativas sejam desenvolvidas com o suporte de tecnologia e viram como possibilidade o uso da ferramenta. Em relação à questões quanto ao uso da ferramenta, os resultados sobre a utilização da ferramenta como suporte para atividade foram: $85 \%$ consideraram o uso da ferramenta satisfatória e $15 \%$ alegaram que a ferramenta ajudou um pouco.

Um estudante citou o e-mail como forma de suporte com tecnologia para práticas colaborativas. Sobre a importância dessas práticas colaborativas, os alunos julgaram a tecnologia com poder de dar maior praticidade no processo de elaboração de questões, assim como a resolução destes instrumentos, dispensando a grande quantidade de papel. Já quando perguntamos sobre a percepção dos estudantes acerca da importância da aprendizagem colaborativa ou aplicação de técnicas de práticas pedagógicas colaborativas nos processos de ensino e aprendizagem numa escala de 1 Nem um pouco importante a 5 - Extremamente importante, obtivemos que $1 / 2$ julgaram como 1 - Extremamente importante e os $1 / 2$ restantes julgaram como 3 - Média importância e 4 - Muito importante.

\footnotetext{
${ }^{3}$ Segundo Prova Brasil (2011), o Tratamento da Informação é campo é essencial para o desenvolvimento do cidadão contemporâneo e está conectado a outros campos do conhecimento. O trabalho possibilita ao aluno a oportunidade de organizar e apresentar dados em forma de gráficos ou tabelas e fazer interpretações sobre as informações neles contidas.
} 
Em uma escala de 1 - Pouco significativa a 5 - Muito significativa, 100\% dos alunos consideraram a atividade de médio para muito significativa, como ilustra o relato de um aluno: "A atividade foi muito boa pois essa possibilidade de usarmos a tecnologia como ferramenta em sala de aula [..] Tive algumas dificuldades na elaboração de algumas perguntas no formulário do meu grupo [...] espero que essa ferramenta seja mais usada na sala de aula". O uso de formulário online ajudou os grupos a trabalharem em colaboração para elaboração das questões.

Observamos, durante a aplicação da atividade, a dificuldade de elaborar as questões, assim como a satisfação por conhecer e/ou utilizar uma ferramenta de auxílio na elaboração das atividades de suas pesquisas científicas. No geral, os feedbacks foram positivos como mostraram os resultados anteriormente comentados. Aspectos específicos de colaboração foram observados, quais sejam: Relação HomemComputador; Resolução de Problemas; Trabalho em Equipe e Coordenação.

\section{Considerações}

No transcorrer desta atividade, foi possível notar que propor uma aprendizagem de forma colaborativa ainda é um desafio para alguns professores. A sala de aula é um espaço em que as possibilidades de aprendizagem se multiplicam e esse contexto contribui para que a colaboração se efetive. Uma aprendizagem baseada na colaboração corrobora para a construção de um pensamento crítico, maior interação entre os alunoalunos e alunos-professor. Dessa forma, problemas são resolvidos e os alunos garantem maior autonomia para assimilar o conhecimento.

Nas duas experiências, percebemos a satisfação de alunos e professores no decorrer de toda a atividade. O objetivo inicial de tornar o processo de responder questionários online mais engajador, colaborativo e significativo foi alcançado. Todo o trabalho foi recompensado com a empolgação dos alunos para tentar descobrir as respostas das questões que estavam resolvendo e com os resultados de aprendizagem que ocorreram, mesmo com o tempo curto da aplicação dessa proposta.

Utilizar o ambiente online do Google Formulários para incentivar a colaboração e a cooperação entre os grupos foi um diferencial para alunos e professores. Esta ferramenta, assim como toda dinâmica planejada proporcionou ao aluno exercer seu protagonismo, item sinalizado em alguns dos relatos. Outros pontos destacados foram o ambiente propício à criatividade, motivação e autonomia. Sendo assim, como trabalhos futuros, desejamos testar essa solução para diferentes contextos e conteúdos, além de analisar os resultados dos questionários para propor novas soluções de acordo com as necessidades de cada contexto.

\section{Referências}

Dillenbourg, P. (1999) “What do you mean by collaborative learning?”. In: Dillenbourg, P. (Ed.). Collaborative learning: Cognitive and Computational Approaches. Oxford: Elsevier, p.1-19.

Dunne, F.; Honts, F. (1998) “That Group Really Makes Me Think!”. In: Critical Friends Groups and the Development of Reflective Practitioners, ED423228 
VII Congresso Brasileiro de Informática na Educação (CBIE 2018)

Anais do XXIV Workshop de Informática na Escola (WIE 2018)

Ellis, C.A.; Gibbs, S.J. e Rein, G.L. (1991) “Groupware: some issues and experiences". Comunications of the ACM. 34.

Gudwin, Ricardo Ribeiro. “Aprendizagem Ativa”. Disponível em: <http://faculty.dca.fee.unicamp.br/gudwin/activelearning>. Acesso em: 08 jun 2018.

Honório, H. L. G.; Scortegagna, L. "Sala de aula invertida na prática: implementação e avaliação no ensino de matemática”. Anais do Workshop de Informática na Escola, v. 23 , n. 1 , p. 31,27 out. 2017.

Lima, M. S. S. et al. "Aplicativo de Desenho do Google Drive: uma análise com foco na aprendizagem colaborativa com suporte computacional". Anais do Workshop de Informática na Escola, v. 22, n. 1, p. 387, 7 nov. 2016.

Novak, J. D; Cañas, A. J. (2010) "A teoria subjacente aos mapas conceituais e como elaborá- los e usá-los”. Práxis Educativa, Ponta Grossa, v.5, n.1, p 9-29, jan.-jun.

Piaget, J, "Epistemologia Genética”. São Paulo: Martins Fontes, 1990.

Scharle, Ágota; Szabó, Anita. (2000) "Learner autonomy: a guide to developing learner responsibility". Cambridge: CUP.

Vygotsky, L. S. (1998) "A formação social da mente: o desenvolvimento dos processos psicológicos superiores”. $6^{\mathrm{a}}$ ed. São Paulo: Martins Fontes. 